\title{
The Effect of Prehospital ECGs on Patient Care in STEMI
}

\author{
Caglar Kuas; ${ }^{1}$ Mustafa Emin Canakci ${ }^{2} \odot$
}

\author{
1. Emergency Department, Yildirim Beyazit \\ University Yenimahalle Training and \\ Research Hospital, Ankara, Turkey \\ 2. Emergency Department, Eskisehir \\ Osmangazi University, Eskisehir, Turkey
Correspondence:
Caglar Kuas
Emergency Department
Yildirim Beyazit University Yenimahalle
Training and Research Hospital
Yeni Batı Mah. 2026. Cad. 2367.
Sk. No:4 Yenimahalle/Ankara 06560
E-mail: dr.ckuas@gmail.com

\section{Conflicts of interest: none}

Keywords: emergency department; electrocardiography; prehospital; STEMI

\author{
Abbreviations: \\ ECG: electrocardiogram \\ FMC: first medical contact \\ PCI: primary coronary intervention \\ STEMI: ST segment elevation myocardial \\ infarction
}

Received: February 10, 2021

Accepted: February 21, 2021

doi:10.1017/S1049023X21000467

(C) The Author(s), 2021. Published by

Cambridge University Press on behalf of the

World Association for Disaster and Emergency Medicine.
Kuas C, Canakci ME. The effect of prehospital ECGs on patient care in STEMI. Prehosp Disaster Med. 2021;36(4):499.

To the Editor:

We have read with great interest the recent article "12-Lead Electrocardiograms Acquired and Transmitted by Emergency Medical Technicians are of Diagnostic Quality and Positively Impact Patient Care" by Kotelnik, et al. ${ }^{1}$ Delays in prehospital access to coronary angiography laboratories in patients with suspected ST segment elevation myocardial infarction (STEMI) are an important factor that changes mortality. ${ }^{2}$ I think this study, which investigates the usefulness of a system that will reduce prehospital delays in STEMI patients, is valuable. However, we would like to share some of our thoughts on the study.

Although it was reported that there were 665 patients whose data were investigated in the study and there were 543 patients suitable to evaluate electrocardiograms (ECGs), the presentation of the data of 557 patients whose prehospital time records were reached in Table $1^{1}$ causes confusion. Again in Table $1,{ }^{1}$ prehospital durations of STEMI patients who were correctly diagnosed and missed are given as numerical values, and it is not stated whether there is a statistical difference between these values. In addition, the time between the first medical contact (FMC) and the wig to primary coronary intervention (PCI) is not included among the time records given in Table 1 . It has been reported in previous studies that the time between FMC and PCI is directly related to mortality. ${ }^{3,4}$ Therefore, I think the time between FMC and PCI should be reported in the study.

It is recommended that the first ECG should be taken within 10 minutes after the first contact in patients with suspected STEMI. ${ }^{5}$ The average time spent on imaging in the study was reported as 18 minutes. In a system that aims to reduce prehospital delays in STEMI patients, we think that the reasons for this delay seen in the first imaging should be reported and discussed.

We think this important study on ECG evaluation in prehospital process will contribute to the literature. We are sure that it will remain in place for a long time, since it is a simple and reliable diagnostic test in the diagnosis of STEMI and the prehospital staff are successful.

References

1. Kotelnik V, Pesce K, Masterton WM, et al. 12-lead electrocardiograms acquired and transmitted by emergency medical technicians are of diagnostic quality and positively impact patient care. Prehosp Disaster Med. 2021;36(1):47-50.

2. Ibánez B, James S, Agewall S, et al. 2017 ESC Guidelines for the management of acute myocardial infarction in patients presenting with ST-segment elevation. Rev Esp Cardiol (Engl Ed). 2017;70(12):1082.

3. Żurowska-Wolak M, Piekos P, Jąkała J, Mikos M. The effects of prehospital system delays on the treatment efficacy of STEMI patients. Scand J Trauma Resusc Emerg Med. 2019;27(1):39.

4. Kawakami S, Tahara Y, Noguchi T, et al. Time to reperfusion in ST-segment elevation myocardial infarction patients with vs without prehospital mobile telemedicine 12-lead electrocardiogram transmission. Circ J. 2016;80(7):1624-1633.

5. Diercks DB, Peacock WF, Hiestand BC, et al. Frequency and consequences of recording an electrocardiogram $>10$ minutes after arrival in an emergency room in non-ST-segment elevation acute coronary syndromes (from the CRUSADE Initiative). Am J Cardiol. 2006;97(4):437-442. 